\title{
Effects of The Laser Wavelength on Drilling Process of Ceramic Using Nd:YAG Laser
}

\author{
M. Mutlu' ${ }^{1}$ E. Kacar ${ }^{1,2}$, E. Akman ${ }^{1}$, C. K. Akkan ${ }^{1}$, P. Demir ${ }^{1,2}$, A. Demir ${ }^{1,2}$ \\ ${ }^{1}$ Laser Technologies Research and Application Center Kocaeli University 41380 Kocaeli/Turkey \\ ${ }^{2}$ Faculty of Arts and Science, Department of physics, Kocaeli University 41380 Kocaeli/Turkey
}

Main author email address: mesuremutlu@gmail.com

\begin{abstract}
Laser micro-processing is an enabling technology that facilitates component miniaturization and improved performance characteristics. Alumina ceramic is used in microelectronics in printed circuit fabrication, due to its good dielectric property. Ablation is usually a combination of evaporation and melts expulsion. Material processing with laser is favour because it provides non-contact, low heat input precise method for the formation of small holes with low taper and smooth wall structure. In this study, we report the results of the micro drilling application of alumina ceramic using nanosecond laser for different wavelengths $(532 \mathrm{~nm}$ and $355 \mathrm{~nm})$ in vacuum and atmosphere environment. The effects of power, wavelength and ambient pressure on crater structure were examined.

DOI: $10.2961 / \mathrm{jlmn} .2009 .02 .0002$
\end{abstract}

Keywords: laser, ablation, drilling, alumina ceramic, micromachining

\section{Introduction}

Laser drilling is a non-contact, low heat input precise method for the formation of small holes with low taper and smooth wall structure. Miniaturization of electronic systems entails material micro-process. Alumina ceramic is used in microelectronics in printed circuit fabrication, due to its good dielectric property. Ceramic is very brittle material and it needs sensitive process with little damage to substrate. Perforation of ceramic by conventional methods causes stress on material and hence damage occurs around the holes.

Ablation is usually a combination of evaporation and melts expulsion. Laser ablation has three basic application; film deposition (Pulsed Laser Deposition - PLD), material characterisation laser induced breakdown spectrometry LIBS) and material processing (drilling, cutting, welding surface micro-structuring etc.). In general ablation rate is defined as the depth of removed material per number of laser pulse $(\mu \mathrm{m} /$ pulse) [1]. In laser ablation the laser parameters and ambient conditions affect the ablation rate. At high laser intensity the ablated material efficiently attenuates the incoming laser radiation, called plasma shielding, so reduces the ablation rate. In other words the plasma formation limits the ablation rate at high fluences due to absorption of the incident beam by the plume. Plasma shielding effect has seen in many metal ablation studies [2]. Dependence of ablation rate of aluminium on the laser wavelength $(1064 \mathrm{~nm}, 532 \mathrm{~nm}$ and $355 \mathrm{~nm})$ as increasing laser fluence has been investigated [1].
Maximum ablation rates were obtained with $355 \mathrm{~nm}$, however below a certain laser fluence ablation rate of 1064 $\mathrm{nm}$ is higher than $532 \mathrm{~nm}$. Investigation on dependence of ablation rate of copper on the laser wavelength $(1064 \mathrm{~nm}$, $532 \mathrm{~nm}$ and $355 \mathrm{~nm}$ ) has shown that as increasing laser fluence the maximum ablation rate has been obtained using $532 \mathrm{~nm}$ laser wavelength [3]. However laser ablation mechanism is still completely unexplored. Kononenko et. al. [4], have investigated laser ablation of metals and ceramics in picosecond and nanosecond pulse width in the presence of different ambient atmospheres. Excimer laser ablation of aluminium nitride determined that the ablation rate increases with decreasing ambient pressure and increases with increasing fluence [5].

In laser drilling process high power laser pulses vaporize the substrate material very fast and clean. Depending on the laser drilling application there are three common methods used for laser hole drilling; single pulse, percussion and trepanning (or conventional laser cutting). Each method depends on depth requirement, hole diameter, number of holes, edge quality, production quantity and material nature. Mechanical hole drilling is difficult as the hole size decreases, furthermore laser drilling is limited because of the optical resolution and absorption of the wavelength to provide material ablation.

Different ceramic drilling studies have been carried out for different process conditions. Alumina ceramic and green alumina ceramic sheets with approximately $1 \mathrm{~mm}$ thickness were drilled using laser pulses with $9.5 \mu \mathrm{m}$ and $10.6 \mu \mathrm{m}$ wavelengths. As irradiation wavelength increases, 
the absorption coefficient increases and hence it causes the lower threshold fluence [6]. Excimer laser (KrF, $248 \mathrm{~nm})$ was used to drill Aluminium nitride (AlN) ceramics with $635 \mu \mathrm{m}$ thickness applying different design of the experiment providing with or without a metallization layer deposited on the hole walls [7]. Another study was performed with coated (chromium and gold) and uncoated alumina with $635 \mu \mathrm{m}$ thickness in order to use in different circuits [8]. Depth-width ratio of hole is important in laser drilling process. Rather thick $(10 \mathrm{~mm})$ alumina ceramic was studied using pulsed Nd:YAG laser with $1.064 \mu \mathrm{m}$ wavelength to observe hole characteristics with different parameters. In a specific peak power and pulse duration values obtained holes exhibits negative taper values [9]. Extension of the ablation process to machining through holes cause damage to the substrate around the exit hole [7]. Laser drilling of Ni-YSZ has come out that the material nature affects the laser ablation rate. Laser drilling of $\mathrm{Ni}$ YSZ cermets has poor quality and ablation rate of green ceramic is higher than the ablation rate of sintered state of NiO-YSZ subtrate [10].

Besides the hole taper (cylindrical shape degree) the spatter situation, which appear due to the incomplete expulsion of the ejected material from the drilling site, express the hole quality. Molten material resolidifies and adheres on the material surface around the hole periphery. In order to prevent spatter and microcracks during the laser machining, many techniques based on either chemical or physical mechanisms have been developed [11-12]. Also the influence of the temporal pulse train shaping is investigated on the material ejection [13-14]. Low et al. [13] performed spatter-free laser percussion drilling closely spaced array holes. Also Sharp et al. [15] applied another antispatter technique for laser drilling.

The aim of this study is to obtain holes small enough with high quality, in order to ensure needs in microelectronic (different sectors). For this reason the effect of drilling parameters (laser wavelength, operation pressure) on the hole quality is examined. Alumina ceramic plates with $800 \mu \mathrm{m}$ thicknesses is drilled using pulsed Nd:YAG laser.

\section{Experimental Procedure}

In this study $\mathrm{Nd}$ :YAG Surelite Continuum laser system is used to investigate the drilling process of alumina ceramic. Duration of laser pulse is $6 \mathrm{~ns}$ and frequency is $5 \mathrm{~Hz}$. Drilling processes were carried out using $532 \mathrm{~nm}$ and $355 \mathrm{~nm}$ laser irradiation wavelengths. Ambient pressure was arranged to $2.3 \times 10^{-5}$ Torr, 0.67 Torr and 760 Torr pressures. 200 pulses were carried out for each crater formation. Crater investigations such as crater diameter, depth and aspect ratio (depth/diameter) were performed at four average laser powers. Applied laser power values were measured by power meter placed in front of the AR coated window, outside of the vacuum chamber. Two different antireflective windows were used to deliver the beam into the vacuum chamber for each laser irradiation wavelength (532 $\mathrm{nm}$ and $355 \mathrm{~nm}$ ). Diameter of the laser beam was reduced from $9.8 \mathrm{~mm}$ to $3 \mathrm{~mm}$ using an iris as a mask. Mask aperture has been used in a few studies to shape the laser beam [16, 17]. Then $4 \mathrm{X}$ magnifier microscope objective were used to focus the laser beam on to the ceramic substrate. The laser beam mode is $\mathrm{TEM}_{10}$. The spot size of the laser beam on the ceramic substrate is $50 \mu \mathrm{m}$. Alumina ceramic plate was controlled by computer controlled motion system. Experimental setup is given in Fig. 1. The applied parameters in the experiments are given in Table1.

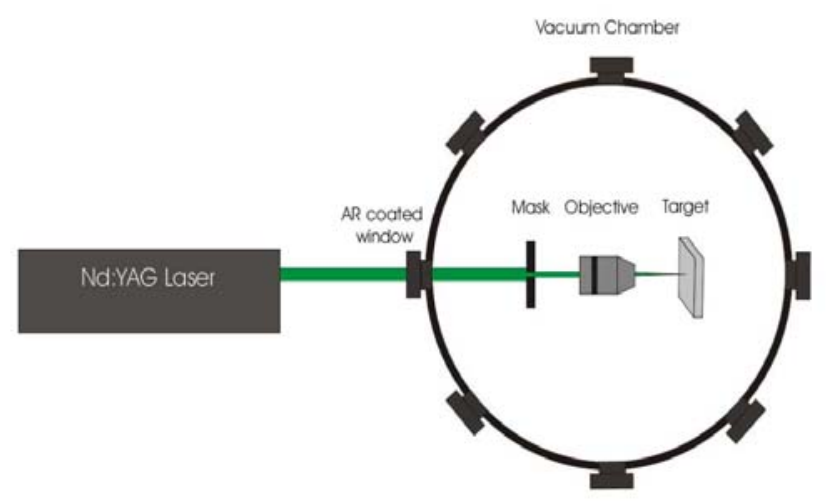

Fig.1 Experimental setup includes Nd:YAG laser, vacuum chamber and optical system.

Pressure was decreased to $10^{-5}$ Torr with rotary and turbo molecular pump in vacuum chamber system. Vacuum chamber has cylindrical form with $100 \mathrm{~cm}$ diameter and 75 cm height.

Table1. Wavelength, power and pressure parameters of experimental study.

\begin{tabular}{|c|c|c|c|}
\hline Frequency & $\begin{array}{c}\text { Laser Wavelength } \\
(\mathrm{nm})\end{array}$ & $\begin{array}{c}\text { Laser Power } \\
(\mathrm{mW})\end{array}$ & $\begin{array}{c}\text { Pressure } \\
\text { (Torr) }\end{array}$ \\
\hline \hline $5 \mathrm{~Hz}$ & $355 \mathrm{~nm}$ & 30 & 0.000023 \\
& $532 \mathrm{~nm}$ & 90 & 0.67 \\
& & 150 & 760 \\
& & 210 & \\
\hline
\end{tabular}


Laser drilled crater profiles of alumina ceramic performed by applying 200 laser pulses. Dektak 6M profilometer has been used to measure the images of craters. Fig. 2. shows a series of crater profiles as increasing average power $(30,90,150$ and $210 \mathrm{~mW})$. Each consecutive two craters were obtained with same operation parameters.

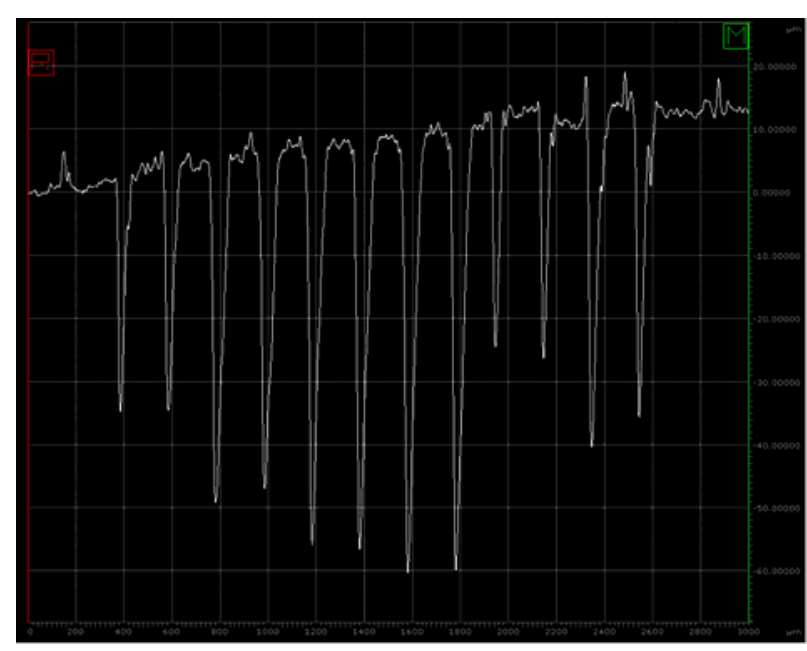

Fig. 2 A series of crater profiles obtained with Dektak 6M profilometer.

\section{Results and Discussions}

In this study craters are produced by applying 200 pulses on the substrate. The average crater depths and diameters are investigated at $30,90,150$ and $210 \mathrm{~mW}$ average power. The average crater depth relation with average power obtained using $532 \mathrm{~nm}$ and $355 \mathrm{~nm}$ laser wavelengths are represented in Fig.3. As the average power is increased the average crater depth increase non-linearly. Both two wavelengths and also each ambient pressures show similar characteristics. The non-linearity, in other words the saturation of the ablation with respect to power increment is observed in many literatures because of plasma shielding effect. In this study the plasma shielding effect is dominant when using $355 \mathrm{~nm}$ laser radiation wavelength at 760 Torr atmospheric pressure.

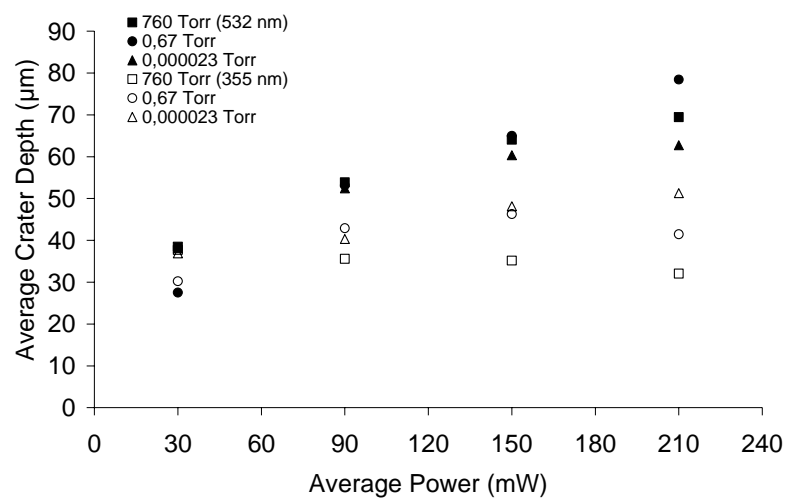

Fig. 3 Average crater depth as a function of average power obtained with using $532 \mathrm{~nm}(\mathbf{\square}, \bullet, \mathbf{\Delta}), 355 \mathrm{~nm}(\square, \circ, \Delta)$ for 760 Torr $(\boldsymbol{\square}, \square), 0.67$ Torr $(\bullet, \circ)$ and $2.3 \times 10^{-5}$ Torr $(\boldsymbol{\Delta}, \Delta)$ ambient pressures.

In general ablation rate is defined as the ratio of depth per number of laser pulse. However there is a study that the removed volume was taken as an ablation rate [18]. In this study we measured both depth and diameter to observe the aspect ratio dependence on operation power. The variation of crater diameter as a function of average power is shown in Fig. 4. Crater diameter obtained at atmospheric condition (760 Torr) exhibits deviation from linear increment for both two wavelengths.

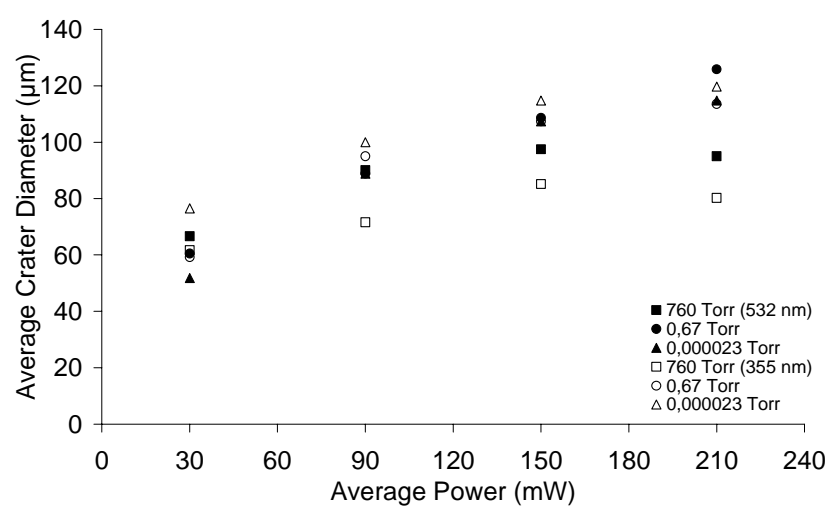

Fig. 4 Average crater diameter as a function of average power obtained with using $532 \mathrm{~nm}(\mathbf{\square}, \bullet, \mathbf{\Delta}), 355 \mathrm{~nm}(\square, \circ, \Delta)$ for 760 Torr $(\boldsymbol{\bullet}, \square), 0.67$ Torr $(\bullet, \circ)$ and $2.3 \times 10^{-5} \operatorname{Torr}(\boldsymbol{\Delta}, \Delta)$ ambient pressures.

The variation of aspect ratio with average power is given in Fig. 5. The craters produced using $355 \mathrm{~nm}$ radiation wavelength represents that the crater diameters increase more than the crater depth. 


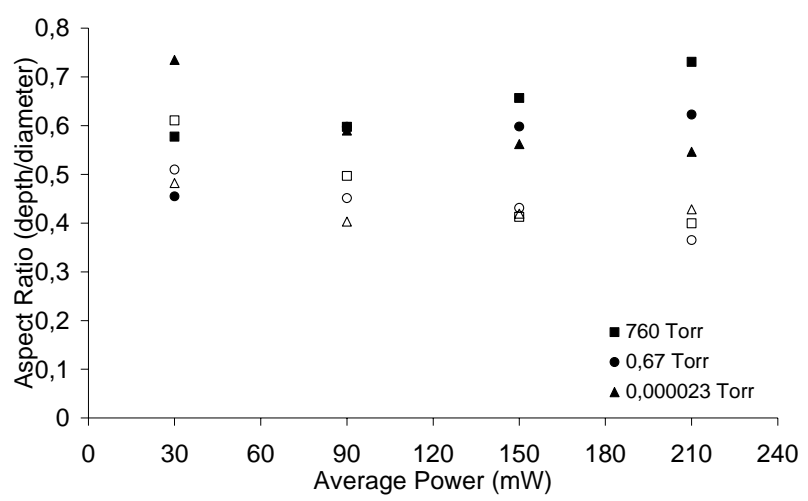

Fig. 5 Relationship between aspect ratio and average power obtained with using $532 \mathrm{~nm}(\boldsymbol{\bullet}, \bullet, \boldsymbol{\Delta}), 355 \mathrm{~nm}(\square, \circ, \Delta)$ laser wavelength for 760 Torr, 0.67 Torr and $2.3 \times 10^{-5}$ Torr ambient pressures.

Pressure dependence on drilling of alumina ceramic investigation is given in Fig. 6. In general the crater diameter is decreased when ambient pressure is increased. However the effect of ambient pressure increment on crater depth is not clear as shown in Fig. 7.

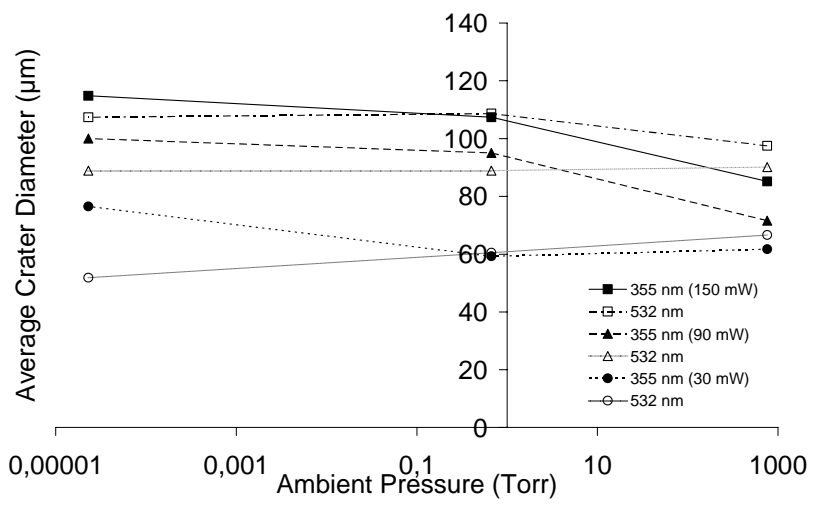

Fig. 6 Average crater diameter as a function of ambient pressure.

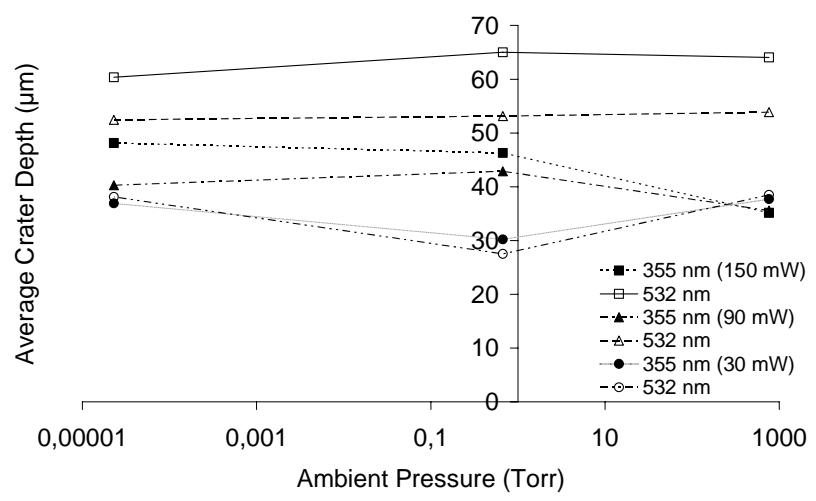

Fig. 7 Average crater depth as a function of ambient pressure.

\section{Conclusion}

In this paper alumina ceramic plates with $800 \mu \mathrm{m}$ thicknesses were drilled using pulsed Nd:YAG laser. The effects of average power, laser radiation wavelengths and ambient pressure on crater depth and diameter were investigated. Ceramic drilling examinations show that when process powers increase the crater depth and diameter increase non-linearly. This manner may occur due to the formation of the plasma above the alumina ceramic that blocks the laser beam. Crater depth increment declinations of $355 \mathrm{~nm}$ are more evident than $532 \mathrm{~nm}$ wavelength operation. However crater diameter increment declinations at 760 Torr ambient pressure are more evident than the other pressure values for both $532 \mathrm{~nm}$ and $355 \mathrm{~nm}$. The crater depth/diameter ratio decrement express that the diameter increment is more than the depth increment for $355 \mathrm{~nm}$ process wavelength. The ambient pressure effect on crater formation shows that when pressures increase the obtained crater diameters decrease generally. However depth behaviour is not clear. Detailed pressure investigations must be performed with more process data to understand this mechanism.

\section{Acknowledgements}

This work is supported by TUBITAK Project under contact 107T566. We are grateful for supporting material (Alumina Ceramic) with Professor E. Suvaci. The authors would like to thank The Scientific and Technological Research Council of Turkey, Marmara Research Centre for permitting us to use their laboratories. Also the authors would like to thank to the reviewers for their constructive comments.

\section{References}

[1] L.Tunna, W.O'Neill, A.Khan, C.Sutcliffe, Analysis of laser micro drilled holes through aluminium for micromanufacturing applications, Optics and Lasers in Engineering 43) 937-950, 2005.

[2] J.M.Vadillo, J.M. Fernandez Romero, C. Rodriguez and J.J. Laserna, Effect of Plasma Shielding on Laser Ablation Rate of Pure Metals at Reduced Pressure, Surface And Interface Analysis, 27, 1009-1015, 1999.

[3] L.Tunna, A.Kearns, W.O'Neill, C.J.Sutcliffe Micromachining of copper using $\mathrm{Nd}$ :YAG laser radiation at 1064,532 , and $355 \mathrm{~nm}$ wavelengths, Optics \& Laser Technology 33, 135-143, 2001.

[4] T.V. Kononenko, S.V. Garnov, S.M. Klimentov, V.I. Konov, E.N. Loubnin, F. Dausinger, A. Raiber, C. Taut, Laser ablation of metals and ceramics in picosecondnanosecond pulse width in the presence of different ambient atmospheres, Applied Surface Science, 109/110, $48-51,1997$. 
[5] J.K.Lumpp and S.D.Allen, Excimer Laser Ablation of Aluminium Nitride, J. Materials Research, Vol.12, pp 218225, January 1997a.

[6] K.Imen and S.D. Allen, Pulse CO Laser Drilling of Green Alumina Ceramic, IEEE Transactions On Advanced Packaging, Vol. 22, No. 4, November 1999.

[7] J.K.Lumpp and S.D.Allen, Excimer Laser Machining and Metallization of Vias in Aluminum Nitride, IEEE

Transactions On Components, Packaging, and Manufacturing Technology-Part B, Vol. 20, No. 3, August 1997b.

[8] R. Rangel, R. Betancourt, and R. Chávez, Laser Drilling On Alumina-Based Printed Microwave Circuits, Instrumentation and Development Vol. 3 Nr.8/1997.

[9] E. Kacar, M. Mutlu, E. Akman, A. Demir, L. Candan, T. Canel, V. Gunay, T. Sinmazcelik, Characterization of the drilling alumina ceramic using $\mathrm{Nd}: \mathrm{YAG}$ pulsed laser, Journal of Materials Processing Technology, In press.

[10] Gurauskis et al, "Laser drilling of Ni-YSZ cermets", Journal of the European Ceramic Society 28 (2008) 26732680

[11] Guo, D., Cai, K., Yang, J., Huang, T., 2003. Spatterfree laser drilling of alumina ceramics based on gelcasting technology. Journal of European Ceramic Society 23, 1263-1267.

[12] Orita, N., 1988. Laser cutting method for high chromium steel and a device to carry out that method. US Patent 4, 774, 392.

[13] Low, D.K.Y., Li, L., Corfe, A.G., 2001a. Spatter-free laser percussion drilling of closely spaced arrayholes. International Journal of Machine Tools and Manufacture 41, 361-377. 341.

[14] Low, D.K.Y., Li, L., Byrd, P.J., 2001b. The influence of temporal pulse train modulation during laser percussion drilling. Optics and Lasers in Engineering 35, 149-164.

[15] Sharp, C.M., Mueller, M.E., Murthy, J., 1997. A novel antispatter technique for laser drilling: applications to surface texturing. In: Proceedings of the Sixth International Congress on Applications of Lasers and Electro-Optics, San Diego, pp. 41-50.

[16 J. Greuters and N.H. Rizvi, Laser micromachining of optical materials with a $157 \mathrm{~nm}$ fluorine laser, Proc. SPIE, Vol. 4941, 77, 2003

[17] N.H.Rizvi, Production of novel 3D microstructures using excimer laser mask projection techniques, Proceedings of the SPIE Conference on Design, Test and Microfabrication of MEMS and MOEMS, Vol. 3680, 1999, pp. $546-552$

[18] H. Horisawa, H. Emura, N. Yasunaga, Surface machining characteristics of sapphire with fifth harmonic YAGlaser pulses, Vacuum 73, 661-666, 2004.

(Received: June 16, 2008, Accepted: April 21, 2009) 